\title{
ESTUDO DA DIAFILTRAÇÃO SEGUIDA DE ULTRAFILTRAÇÃO NA OBTENÇÃO DE LEITE CONCENTRADO COM BAIXO TEOR DE LACTOSE
}

\author{
Rebeca dos Reis Magalhães Azevêdo ${ }^{1}$; Hélia Lucila Malta ${ }^{2}$
}

1. Bolsista Fapesb, Graduanda em Engenharia de Alimentos, Universidade Estadual de Feira de Santana, e-mail: rebecareisengal@gmail.com

2. Orientador, Departamento de Tecnologia, Universidade Estadual de Feira de Santana, e-mail: hlmalta@uefs.br

PALAVRAS-CHAVE: ultrafiltração, diafiltração, lactose.

\section{INTRODUÇÃO}

O leite pode ser considerado o alimento mais completo da natureza e o único que satisfaz as necessidades dos recém-nascidos de sua espécie nos primeiros meses de vida (Borges et al., 2001). Entretanto, cada vez mais indivíduos vêm apresentando dificuldades na ingestão de lácteos. Buscando atender então esse público a hidrólise se mostra promissora no desenvolvimento de produtos sem lactose em suas composições, oferecendo ainda vantagens tecnológicas, na medida em que diminui os riscos de cristalização nos derivados lácteos e aumenta o poder adoçante (Longo, 2006). Inicialmente quando se deseja a concentração de um produto, o método clássico é a Evaporação, tendo esse método a desvantagem da possibilidade de ocorrência da reação de Maillard. Desse modo a tecnologia por separação utilizando membranas se apresenta como uma ferramenta para manutenção das características do produto final (Alves et al., 2014). O processo de separação em baixas temperaturas, sem mudança de fase, faz da filtração por membranas (ultrafiltração, nanofiltração, diafiltração) uma solução muito mais econômica que métodos convencionais (Gea, 2012).

\section{MATERIAL E MÉTODOS OU METODOLOGIA}

Foi utilizado um sistema de ultrafiltração da marca Sartorius composto por uma membrana Vivaflow 50 de polietersulfona (PES) com peso molecular de corte de 3 e 10 kDa e uma bomba peristáltica Masterflex. A partir desse sistema foram feitos os ensaios de diafiltração e ultrafiltração, assim como as análises de permeabilidade hidráulica da membrana. As diafiltrações/concentrações foram realizadas após a hidrólise do leite realizada com a enzima beta-galactosidase, por $53 \mathrm{~min}$, a $26^{\circ} \mathrm{C}$, com concentração enzimática de $1,78 \mu \mathrm{l} / \mathrm{ml}$. Foram realizadas avaliações físico químicas na matéria prima (densidade, $\mathrm{pH}$, acidez titulável, gordura, glicose, lactose, proteínas, análise de extrato seco), na amostra após hidrólise (Glicose) e após diafiltração/concentração (glicose, sólidos e proteína) conforme referido por INSTITUTO ALDOLFO LUTZ (2005). 


\section{RESULTADOS E/OU DISCUSSÃO}

\section{Permeabilidade das Membranas}

A determinação da permeabilidade foi efetuada com a passagem contínua de água deionizada no sistema (diafiltração), anotando-se a massa do retido, por minuto, durante 30 minutos, para cada pressão disponível no sistema $(1,0 ; 1,5 ; 2,0$ e 2,5 bar), calculando-se assim o fluxo médio. Foram analisadas duas membranas: uma de 10KDa, já utilizada em estudos anteriores e uma de $3 \mathrm{KDa}$, ou seja de menor massa molar de corte. A membrana de $3 \mathrm{kDa}$, nunca utilizada anteriormente, apresentou uma permeabilidade hidráulica de 2,94E-0,5 $\mathrm{g} / \mathrm{m}^{2}$.s.Pa, mostrando maior resistência para passagem de fluido que a membrana de $10 \mathrm{kDa}$ que teve permeabilidade hidráulica analisada reestabelecida em 3,88E-0,5 g/m².s.Pa.

\section{Diafiltração/Concentração}

O leite já hidrolisado passou por processo de diálise (diafiltração), onde água deionizada era alimentada ao sistema por um período de quatro horas, anotando-se a massa permeada a cada cinco minutos para determinação do fluxo. Após diafiltração, que teve duração de 4 horas o leite foi concentrado com fator de concentração 4, pressão de 2,5 bar. Inicialmente foram analisados os fluxos médios de saída de permeado na diafiltração e concentração, sendo eles $3,94 \mathrm{~g} / \mathrm{m}^{2}$.s e $3,89 \mathrm{~g} / \mathrm{m}^{2} . \mathrm{s}$, consecutivamente. Tais fluxos foram obtidos tendo a quantidade em massa de permeado por tempo (a cada 5 minutos), e a área da membrana, de $0,0005 \mathrm{~m}^{2}$. Os fluxos foram próximos, podendo a pequena diferença entre eles ser explicada pela passagem contínua de água na diafiltração facilitando a saída de permeado, visto que auxilia na redução de acúmulo de materiais na membrana.

Gráfico 01: Fluxo por tempo medidos durante Diafiltração

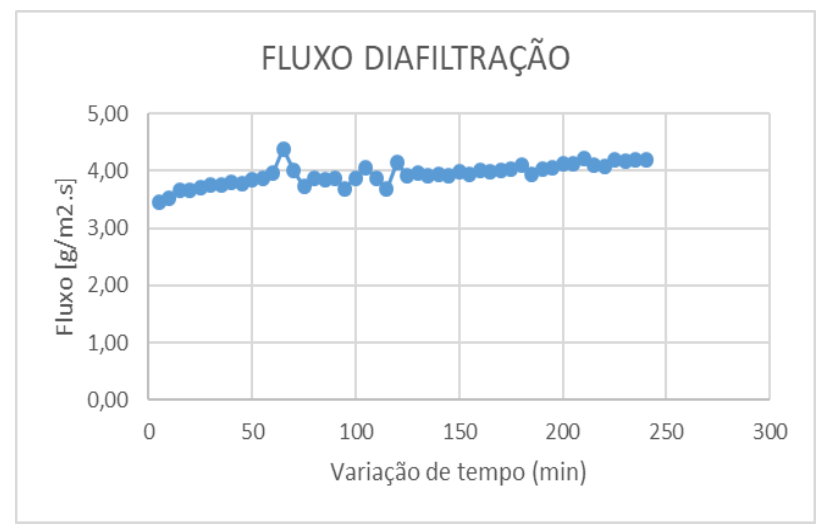


Figura 02: Fluxo por tempo medidos durante Concentração

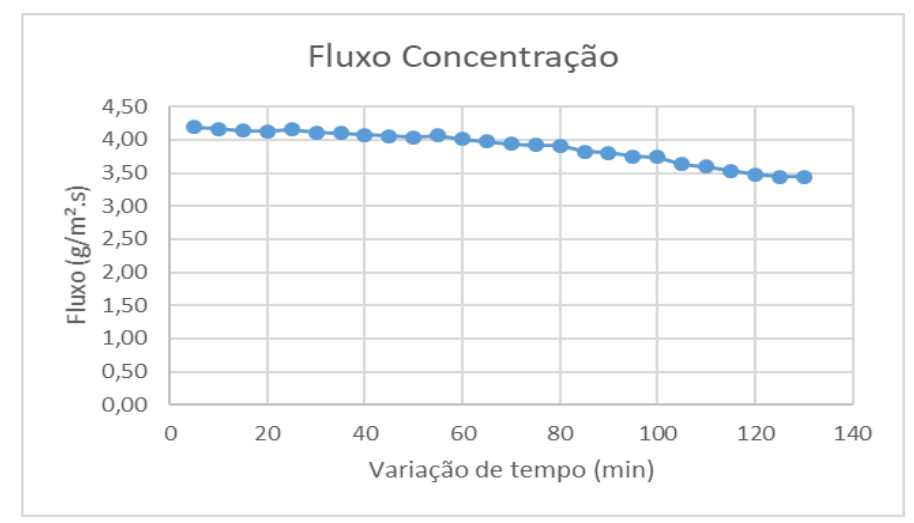

Através desses gráficos podemos observar um declínio continuo do fluxo durante a concentração enquanto na diafiltração temos um aumento no fluxo. Pode-se explicar esse efeito no acréscimo positivo que a diafiltração possui em evitar acúmulo de sólidos na membrana, o chamado fouling. Após a diafiltração e concentração foram feitas as análises físico químicas no concentrado obtido e definidas as porcentagens de retenção para glicose, proteína e sólidos. Os resultados estão apresentados na Tabela 01.

Tabela 01: Comparações Retenção (\%) de componentes do leite após os processos de Concentração por membrana e diafiltração seguida de concentração

\begin{tabular}{ccc}
\hline Parâmetro Avaliado & $\begin{array}{c}\text { Diafiltração/ } \\
\text { Concentração }\end{array}$ & Apenas Concentração \\
\hline PROTEÍNA & $93,50 \%$ & $94,00 \%$ \\
GLICOSE & $9,90 \%$ & $26,40 \%$ \\
SÓLIDOS & $27,18 \%$ & $48,12 \%$ \\
\hline
\end{tabular}

Observou-se que a concentração de proteína continuou praticamente igual, com um alto grau de retenção, explicado pelo seu maior peso molecular, já que mesmo com a diafiltração, que aumenta as chances de permear as soluções, o tamanho das moléculas de proteína ainda são maiores que o corte da membrana, ficando assim ainda retidas. A glicose foi altamente permeada, restando menos que $10 \%$ de glicose na amostra, sendo então a diafiltração uma ferramenta promissora na produção tecnológica de produtos derivados de leite com teor reduzido de açúcares ou que sejam prejudicados com a presença de açúcares em processos que utilizem calor, como a produção de leite em pó sem lactose. Esse resultado é consistente com os dados obtidos por Pagno et al. (2009), 
onde observou-se uma redução de 30 para $10 \%$ de retenção de lactose, quando aplicada a Diafiltração.

\section{CONSIDERAÇÕES FINAIS}

A membrana de $10 \mathrm{KDa}$ se mostrou mais adequada ao processo, já que possui um maior fluxo de permeado, dificultando a ocorrência de entupimentos e incrustações. Após análises, apesar de mantidas quase sem mudanças nas concentrações de proteína, percebeu-se a intensificação da rejeição da glicose ocorrida durante o processo de diafiltração se comparado a uma ultrafiltração convencional. Esse fato suscita um estudo sobre a redução do teor de lactose do leite somente através da ultrafiltração, sem a necessidade de realização de uma hidrólise inicial, pois é possível que a lactose também seja permeada, assim como a glicose. Tal fato seria interessante para a economia no processo, assim como evitaria o aquecimento do leite, realizado no momento de inativação enzimática, que necessita de controle para não ocasionar um escurecimento do produto.

\section{REFERÊNCIAS}

ALVES, et al. Soro de leite: tecnologias para o processamento de coprodutos. Rev. Inst. Laticínios Cândido Tostes, Juiz de Fora, v. 69, n. 3, p. 212-226. Mai/jun, 2014.

BORGES, et al. Produção Piloto de Concentrados de Proteínas de Leite Bovino: Composição e Valor Nutritivo. Braz. J. Food Technol., 4:1-8, 2001.

GEA FILTRATION. Filtração por membranas. Catálogo de exposição, 2006.

INSTITUTO ADOLFO LUTZ, Normas analíticas do Instituto Adolfo Lutz - Métodos físico químicos para análise de alimentos. São Paulo: 2005.

LONGO, G. Influência da adição de lactase na produção de iogurte. 2006. Dissertação (Mestrado em Tecnologia de Alimentos) - Setor de Tecnologia, Universidade Federal do Paraná, Curitiba, 2006.

PAGNO, et. al. Obtenção de Concentrados protéicos de soro de leite e caracterização de suas propriedades funcionais tecnológicas. Alim. Nutr. Araraquara v.20, n.2, p. 231-239, abr./jun. 2009. 